\title{
Explanation by status as empty-base explanation
}

\author{
Yannic Kappes ${ }^{1}$ (1)
}

Received: 23 April 2020 / Accepted: 5 October 2020 / Published online: 9 November 2020

(c) The Author(s) 2020

\begin{abstract}
This paper explores the practice of explanation by status, in which a truth with a certain status (i.e. necessary status, essential status, or status as a law) is supposed to be explained by its having that status. It first investigates whether such explanations are possible. Having found existing accounts of the practice wanting, it then argues for a novel account of explanation by status as empty-base explanation. The latter notion captures a certain limiting case of ordinary explanation so that according to the emptybase account, explanation by status can be fruitfully understood as a corresponding limiting case of ordinary explanation. One way in which the empty-base account is argued to be superior to other treatments of explanation by status is that it allows for a principled assessment of the possibility of particular kinds of explanation by status. Thus, one result of the present discussion is that explanation by essential status and status as a law are possible, while explanation by merely necessary status is not.
\end{abstract}

Keywords Explanation by status - Empty-base explanation · Zero-grounding · Explanation by necessity · Essentialist explanation - Explanation by law

\section{Introduction}

This paper explores an explanatory practice I call 'explanation by status' and its viability. In explanations by status, a truth that has a certain status, e.g. modal status, is supposed to be explained by its having that status. Here is a schematic list of the kinds of explanation by status that this paper deals with:

(Explanation by Necessity) That it is necessarily true that $P$ explains why $P$. (Explanation by Law) That it is a (descriptive) law that $P$ explains why $P$. (Explanation by Essence) That it is an essential truth that $P$ explains why $P{ }^{1}$

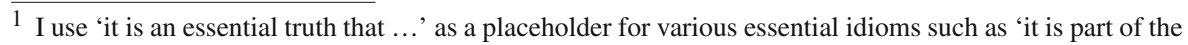
essence of ... that ...'.

$凶$ Yannic Kappes

yannickappes@gmail.com

1 Department of Philosophy, University of Hamburg, Überseering 35, 22297 Hamburg, Germany
} 
The status notions, e.g. the notions of modality and law, can be varied to obtain related kinds of explanation by status. ${ }^{2}$ Besides proposals concerning explanation by necessity, law, and essence, some further proposals that fall into the broader category of explanation by status have been advanced in the literature, but here I am only concerned with explanation by necessary status, essential status, and law, as characterized by the schemata. ${ }^{3}$

This is the plan for the paper: The remainder of this section introduces some basic assumptions about explanation in general and structures the following investigation around some initial questions. Section 2 discusses reasons against the existence of explanation by necessary status, while Sect. 3 discusses reasons in favor. Section 4 investigates to what extent the preceding considerations generalize to the cases of explanation by essential and law status and then considers two reactions to the discussion: According to Kappes and Schnieder (2016), explanations by status are not possible, but pointing out the status of a proposition can play a role related to explanation. According to Glazier (2017a,b), explanations by status require sui generis explanatory relations to hold between the explanandum and the corresponding status ascribing proposition. ${ }^{4}$ Having found these reactions wanting, Sect. 5 introduces the notion of an empty-base explanation and shows how explanation by status can be fruitfully understood as empty-base explanation. I argue that my proposal deals well with the considerations of the previous sections and compares favorably with Glazier's rival proposal. But while it makes sense of explanation by status in general, it also provides an argument against the possibility of explanation by necessary status in particular. As a remedy, I suggest that proposals involving explanations by modal status are best substituted by explanations by status involving notions like essence or lawhood.

To discuss explanation by status, some general assumptions about explanation need to be introduced. First, I will be exclusively concerned with explanation why, rather than, for example, explanation how or what. Second, there is a well known distinction between the explanandum of an explanation - that what is explained, and the explanans of an explanation - that what does the explaining. But finer distinctions can be made:

"Explanation has a tripartite structure of sources, links, and result. With causal explanation, there is the structure of causes (such as the rock striking the window), laws (laws of nature), and effect (such as the shattering of the window). Metaphysical explanation has a parallel structure, involving grounds (the more

\footnotetext{
2 For explanation by metaphysical necessity see e.g. Leibniz (1714), van Inwagen (1996) and Rundle (2004) who apply the idea in philosophical theology and to the question of why there is anything at all. Block and Stalnaker (1999) and Hill and McLaughlin (1999) use it in their abductive arguments against dualism in the philosophy of mind, Biggs (2011) builds an abductive epistemology of modality upon it, and Glazier (2017a) uses it in his account of the difference between epistemic and metaphysical necessity. For explanation by natural necessity see Lange (2009a, 2013). For explanation by metaphysical law and law of nature see Kment (2014, ch. 6) and Lange (2009b). For explanation by essence see Rosen (2010), Kment (2014, ch. 6), and Glazier (2017b).

3 See van Inwagen (1996) for explanation by high probability and Leslie (2001) for explanation by value. See footnote 51 for how the present account might be used to evaluate van Inwagen's proposal.

4 Two alternative approaches to explanation by status may be provided by Bertrand's (2019a, b) account of metaphysical explanation by constraint and Kovacs' (2020) unificationist theory of metaphysical explanation that I suspect can be fruitfully applied to understand explanation by status from a unificationist angle.
} 
fundamental sources), principles (metaphysical principles of grounding), and grounded (the less fundamental result)." (Schaffer 2017, 3)

This tripartite view identifies two roles that facts or propositions that belong to the explanans may have: in Schaffer's terms, those of sources and links. ${ }^{5}$ To add a little terminology whose utility will become apparent below, let us call the sources of an explanation taken together its base. In an inclusive sense, we can say that the sources and the link of an explanation why $P$ together explain why $P$. In the case of causal explanation, the distinction is particularly clear: Laws are not causes and vice versa; nevertheless they are both-yet in different roles-involved in causal explanations. ${ }^{6}$ The rough distinction supported by examples like Schaffer's seems intuitively clear, and indeed, if not in Schaffer's terminology, something like the distinction between sources and links is widely recognized in the literature on explanation. ${ }^{7}$

Next, I assume that the tripartite structure of explanation bears the following correspondence to 'because' claims: The left-hand clause of a 'because' claim expresses the explanandum, its right-hand side expresses an explanatory source, and the 'because' claim itself is underwritten by the corresponding explanatory link. ${ }^{8}$ Correspondingly, the sources of an explanation why $P$ are reasons why $P$, but the corresponding explanatory link is (disregarding certain exceptional cases) not a reason why $P .{ }^{9}$

Given these assumptions, let us now turn to three general questions concerning explanation by status:

1. What, if any, is the explanatory role of the status proposition: Is it a reason why the explanandum obtains or an explanatory link?

2. What kind of links occur in explanations by status, and which explanatory notions occur in them?

3. What is the intended scope of the three schemata given above?

It might appear clear that in explanations by status, the status proposition has the role of reason why the explanandum obtains - after all, the status proposition does not seem to link anything to the explanandum. Moreover, when stating such explanations by status, philosophers often assert an instance of ' $P$ because $* P$ ', where ' $*$ ' stands for an operator that expresses the status is question. ${ }^{10}$ We therefore assume for now that these explanatory proposals advance reasons for (or sources of explanations of) the relevant propositions or facts.

In Sect. 5 I will revisit this assumption and propose that we should construe proposals for explanations by status as proposals for what I call empty-base explanations, whose explanatory link is a status proposition. For now, given the assumption that

\footnotetext{
5 I assume that the constituents of explanations are true propositions or facts and I will use these terms interchangeably, unless noted otherwise.

${ }^{6}$ For this example I follow Schaffer in assuming that it is laws (rather than individual instances of, for example, causation) that play the role of link.

${ }^{7}$ E.g. Hempel and Oppenheim (1948), Lewis (1986), Kim (1994), Woodward (2003), and Schnieder (2010).

8 Of course, the explanatory use of 'because' is relevant here. For a treatment of 'because' that supports the assumptions of this paragraph see Schnieder (2010; 2015, 142ff.).

${ }^{9}$ For an extensive treatment of this view see Skow (2016).

${ }^{10}$ For instance, Glazier (2017b, 2873) writes that "[an explanation] will not be an essentialist explanation, if it is not of the form ' $A$ because $t$ is essentially such that $A$ '."
} 
explanations by status advance reasons why their explananda obtain, and given what I have said about the relation between reasons why and 'because' claims, we can derive the following schemata from the three schemata at the beginning of this paper:

(Because Necessity) $P$ because it is necessarily true that $P$.

(Because Law) $P$ because it is a (descriptive) law that $P$.

(Because Essence) $P$ because it is an essential truth that $P$.

With respect to the second question, we assume for now that the explanations by status under discussion are supposed to be grounding explanations, which is plausible, given that they seem to be metaphysical explanations. When the arguments for and against explanation by status are on the table, I will consider which of them remain once we lift the assumption that the explanatory relation is grounding, as Glazier (2017a, b) advocates.

With respect to the third question, the candidate answers are that the scope is either restricted only to propositions which possess the status in question (i.e. restricted only to propositions which are indeed necessary, essential or possess law-status) or it is restricted to a subclass of these propositions. The first restriction is mandated by the factivity of 'because' and explanation: Only true propositions can be explained and only propositions that possess the relevant status could in principle be explained by their having that status. On the other hand note that a further restriction of the schemata's scope would constitute a significant intuitive and theoretical burden: Lest the restriction appear arbitrary, it has to be principled somehow, but it is hard to see what such a principle could look like. Moreover, full grounding explanations plausibly satisfy something like deRosset's (2013) "Determination Constraint". The idea behind this constraint is approximately this: If $a$ 's being $G$ is fully grounded in $a$ 's being $F$, there should be no entity that is $F$ but whose being $F$ does not ground its being $G$-if there were such an entity, the explanation of $a$ 's being $G$ in terms of $a$ 's being $F$ would seem incomplete. Something analogous appears to hold for explanation by status: If $[P]$ is fully explained by its being necessary, then there should be no necessary proposition $[Q]$ which is not explained in its being necessary-if there were such a proposition, the explanation of the first proposition in terms of its being necessary would seem incomplete. ${ }^{11}$ There is thus considerable pressure to accept that if a proposition's necessary, essential or law status explains its truth in one case, it should do so in general, and I will assume as much in the following.

\section{Against explanation by modal status}

Under the assumption that the available kind of explanation is grounding explanation, this section offers a number of considerations to motivate that for no $[P],[\square P]$ explains $[P]$ in the sense of figuring in the base of an explanation of $[P]$. In the idiom of reasons, it offers considerations to the effect that for no $[P],[\square P]$ is a reason why

\footnotetext{
11 '[...]' is used to refer to the proposition expressed by the sentence within. In Sect. 3 we will encounter reason to believe that this reasoning must be revised, although in a way that does not affect the following arguments.
} 
$[P] .{ }^{12}$ Correspondingly, I will argue against (all but possibly a few exceptions of) the instances of the following schema (for now, 'because' expresses grounding):

(BECAUSE- $\square$ ) $P$ because $\square P$.

Intuitive doubts: The first reason to doubt the instances of BECAUSE- $\square$ comes from intuition: At least in a certain light, it is hard to see what explanatory value it should have to point out the necessary status of a proposition. Correspondingly, the instances of BECAUSE- $\square$ do not seem particularly plausible. More specifically, it is hard to see how the truth of a proposition should be brought about (and hence be explained) by its necessary truth. Of course, the latter entails the former, but whether the latter explains the former is nevertheless intuitively doubtful. ${ }^{13}$

Perhaps this intuitive worry can be sharpened by considering what the propositions $[P]$ and $[\square P]$ are about. If ' $\square P$ ' can be paraphrased as 'It is necessarily true that $P$ ', the corresponding proposition primarily appears to be about a certain other proposition, namely the proposition $[P]$ and the way in which this proposition is true, namely necessarily. But $[P]$ on the other hand normally concerns something else: For example, $[\square$ (2 is prime)] primarily appears to be about the proposition [2 is prime] and this proposition's being necessarily true. On the other hand, [2 is prime] primarily appears to be about the number 2 and its being prime, and not at all about the proposition [ 2 is prime] or that proposition's being necessarily true. What lies behind the intuition above may then be that the way in which the proposition [ 2 is prime] is true is not explanatorily relevant to 2's being prime; more generally, what $[\square P]$ is primarily about can seem not to be explanatorily relevant to $[P]$.

Grounding elimination rules: Construed as grounding explanations, some paradigmatic cases of explanations by status conflict with Fine's $(2012,63 f$.) influential logic of ground, according to which any proposition that grounds $[P \vee \neg P]$ must either be identical to its true disjunct or ground it. ${ }^{14}$ If there are true instances of BECAUSE- $\square$, ' $P \vee \neg P$ because $\square(P \vee \neg P)$ ' should surely be among them, but since $[\square(P \vee \neg P)]$ is not in general either a true disjunct of $[P \vee \neg P]$ or grounds such a disjunct, these candidates for explanations by status are ruled out by the logic of ground. Since it is hard to see how necessary status could only sometimes explain, we obtain a general argument against explanation by modal status understood as grounding explanation. ${ }^{15}$

Regress: Above I have argued that if ' $P$ because $\square P$ ' is true for some necessarily true ' $P$ ', it should be true for all necessarily true ' $P$ '. Now, since necessity can be iterated, regresses like the following arise:

-2 is prime because $\square 2$ is prime.

$-\square 2$ is prime because $\square \square 2$ is prime

\footnotetext{
12 A possible exception stems from cases that we will encounter in the next section.

13 Cf. Kappes and Schnieder $(2016,556)$.

14 The logic of Fine (2012) captures this idea by postulating elimination rules for the impure logic of ground, for instance the rule $\vee E$, but the idea is also contained in Fine's (2017b) account of grounding in terms of truthmaking.

15 Glazier (2017b) reacts to this problem by postulating further (non-grounding involving) types of explanatory links specific to explanations by status - see below. Note also that some authors simply reject Fine's assumptions about ground, see for example Rosen (2010), Yablo (2014, ch. 4), and Kappes (2020) for further discussion.
} 
- ... etc.

Whether explanatory structures like this have any explanatory value is questionable, and the idea that the truth that 2 is prime is brought about by a series of more and more complex modal truths appears doubtful. ${ }^{16}$ Moreover, while opinion on the matter is divided, a number of philosophers believe that there cannot be infinitely descending grounding chains, at least not without every element in the chain also being grounded in something ungrounded. ${ }^{17}$ But the idea that the elements of the regress are also grounded in something outside it does not help here: On pain of restarting the regress, these grounds must be contingent, which in itself is already dubious, but particularly problematic in the present context: Explanation by modal status is often offered as a kind of particularly good, modally stable and ultimate explanation that contingent explanantia cannot provide. ${ }^{18}$

Furthermore, it seems intuitively plausible that if it is true that $\square P$, then it is also true that $\square \square P$ because $\square P$; this is also supported by the plausible idea that (with possible exceptions), grounding explanations should proceed from less complex to more complex propositions. But this makes matters worse, because if it is true that $\square P$, then we get ' $\square P$ because $\square \square P$ ' from BECAUSE- $\square$ and ' $\square \square P$ because $\square P$ ' from the assumption; together, the two claims violate the asymmetry of grounding.

To avoid these problems, BECAUSE- $\square$ could be restricted and single-box propositions assumed to ground their non-boxed constituent propositions, as well as the corresponding multi-box propositions. Here, I want to commit to the argument from Sect. 1 and submit that the restriction of BECAUSE- $\square$ is not feasible. Also, such a proposal could not claim the potential advantages of the regress discussed in Sect. 3. ${ }^{19}$

Problems for certain theories of modality: According to some theories, all metaphysical necessities can be be grounded in propositions that do not involve modal operators. For example, according to a proposal attributable to Fine (1994), all metaphysical necessities can be grounded in truths about essences. Consider a metaphysical necessity $[\square P]$ and its ground $[Q]$, e.g. an essential truth. Now, essential truths are themselves necessary. ${ }^{20}$ But then $[\square Q]$ is true as well and presumably grounds $[Q]$. Since we assumed a theory according to which all metaphysical necessities can be grounded in other truths, we embark on a regress that once more only seems stoppable in an ad hoc fashion.

Here, not only the explanatory extravagance of the regress is problematic, but the fact that it conflicts with the reductive goal of the kind of theory we assumed: This kind of theory is supposed to show that every metaphysical necessity can ultimately be reduced to or grounded in truths that do not involve metaphysical necessity. But if the regress obtains, this cannot be true: Every essential truth will be further grounded

\footnotetext{
16 Cf. Kappes and Schnieder (2016, 556f.). See Sect. 3 below for a more positive view of the regress.

17 Cf. Rabin and Rabern (2016).

18 See Sect. 3.

19 A referee has suggested to me that the regress could perhaps be stopped by identifying the propositions

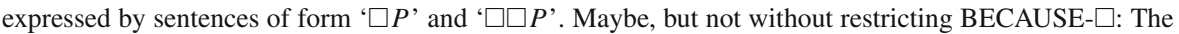
regress arises from the schema by substitution of ' $P$ ' even if we assume that ' $\square 2$ is prime' and ' $\square \square 2$ is prime' express the same proposition. For further discussion of the regress see Sects. 4 and 6 .

20 More generally, one might try to argue that the grounds of metaphysical necessities must themselves be necessary. Note that I call only truths of form ' $\square P$ ' 'necessities' and not all necessary truths.
} 
in its being a necessary truth—no asymmetry seems salvageable that would allow us to claim that metaphysical modality is reduced to essence and not vice versa.

The next problem for grounding explanation by necessary status stems from the paraphrase of necessity as truth in all possible worlds. Given the paraphrase, grounding a proposition in a proposition that expresses its necessary status looks like using a universal quantification ('In all possible worlds: $P$ ') to ground one of its instances ('In this possible world: $P$ '). However, universal quantifications are grounded in all of their instances taken together. ${ }^{21}$ More perspicuously, the following assumptions lead into an explanatory circle:

(Grounding by Necessity) $P$ because $\square P$.

(Grounding by Possible Worlds) $\square P$ because in all possible worlds: $P{ }^{22}$

(Grounding by Instances) (In all possible worlds: $P$ ) partially because in this possible world: $P$.

(@P by $P$ ) (In this possible world: $P$ ) because $P$.

One of these needs to go, and since (Grounding by Possible Worlds) is true by assumption and (Grounding by instances) is supported by the literature, the culprit is either (Grounding by Necessity) or (@P by $P$ ). I submit that (@P by $P$ ) seems at least as plausible as (Grounding by Necessity). ${ }^{23}$

Taking stock: Combined, the foregoing considerations provide a significant challenge for the relevant instances of ' $P$ because $\square P$ '. Although some of the considerations rely on more or less contentious assumptions about the grounds of metaphysical necessities, not only proponents of these assumptions may be confronted with the arguments, because one might think that the feasibility of explanation by modal status should be theoretically robust in the sense of not being threatened by such assumptions. So, in order to work the previous paragraphs into an argument against the instances of ' $P$ because $\square P$ ' that does not rely on the contentious assumptions, one could argue that if the relevant instances of ' $P$ because $\square P$ ' are in general true, this phenomenon should be more theoretically robust than the previous paragraphs suggest.

\section{In favor of explanation by modal status}

Let us now discuss some considerations in favor of explanation by modal status. First, certain instances of ' $P$ because $\square P$ ' and maybe more so ' $[\square P]$ explains $[P]$ ' do have some intuitive appeal. For example, in the right mindset, I can appreciate how 'God exists because they must exist' or 'The first law of thermodynamics holds because it must hold' may seem good candidate 'because'-claims. Moreover, as we have seen in the introduction, a number of philosophers have put explanation by modal status to work. This bolsters the point from intuition, but it also motivates instances of ' $P$ because $\square P^{\prime}$ by revealing their potential theoretically fruitfulness.

\footnotetext{
21 See e.g. Schnieder $(2011,450 f$.$) and Fine (2012,59$ f.).

22 The circle also arises if the propositions $[\square P]$ and [In all possible worlds: $P$ ] are identified. Something analogous holds for (@P by $P$ ).

23 Cf. Kappes and Schnieder (2016, 556).
} 
Ultimate explanation: Here is one respect in which explanation by modal status may be theoretically fruitful: Consider a necessary proposition $[P]$ and the hierarchy of associated box-propositions $[\square P],[\square \square P]$, etc. again. Note first that it would surely be desirable to somehow explanatorily connect the iterated box-claims-this the regress discussed in the previous section achieves. Furthermore, there is a potential positive flipside to the regress: Some philosophers think that explanation by metaphysical necessity is ultimate, i.e. such that with respect to its explanandum, no relevant 'why' questions are left unanswered by it. ${ }^{24}$ This idea can be spelled out as follows: An explanation (or set of explanations) why $P$ in terms of reasons $\Omega$ is ultimate iff all reasons why $P$ contained in $\Omega$ are fully explained by reasons contained in $\Omega$.

Now, if the explanatory regress in question is not vicious, then it may afford such an ultimate explanation. Still, given that the regress does not seem particularly explanatorily valuable, it is unclear how desirable an ultimate explanation in the above sense really is. Moreover, according to Bliss (2013), explanatory regresses are vicious relative to an explanatory goal if they fail to afford that explanatory goal. So, at least with respect to the explanatory goal of "explaining away" necessity, the regress is vicious: According to it, it is "boxes all the way down".

Exceptional cases: There are instances of ' $P$ because $\square P$ ' that arise from the combination of certain prima facie plausible grounding principles:

(1) $\square$ (There are facts) < It is a fact that $\square$ (There are facts) $<$ There are facts.

(2) $\square$ (There are $P$ such that $P$ ) $<$ There are $P$ such that $P$.

While these examples may involve grounding principles that are inconsistent with other plausible grounding principles (cf. Fine (2010) and Krämer (2013)) and hence might have to be discarded anyways, more can be said here:

First, the intuitive worries with respect to the intended instances of ' $P$ because $\square P^{\prime}$ ' can be upheld. Second, the examples somehow miss the point, because contrary to how it behaves in the intended instances of explanation by necessary status, the necessity of the propositions itself does not seem to play the right explanatory role in the present cases. To see this, consider for example (2): According to the underlying grounding principle, true existential generalizations into sentence position are fully grounded by their true instances. ${ }^{25}$ But since, for example, $[\nabla$ (There are $P$ such that $P)]$ is also a true instance of [There are $P$ such that $P$ ], it also fully grounds the latter.

So, in a sense, in this case it is not the necessity of [There are $P$ such that $P$ ] (as opposed to e.g. its possibillity) that explains why there are $P$ such that $P$, it just happens to be the case that $[\square$ (There are $P$ such that $P]$, just like $[\diamond$ ( There are $P$ such that $P$ )], is a true instance of [There are $P$ such that $P$ ] and hence grounds it (analogous considerations hold for (1)). ${ }^{26}$ Just as we would not conclude on the basis

\footnotetext{
24 Cf. Rundle (2004, ch. 5).

25 Cf. Krämer (2013).

26 Contrastivity might help clarify the point: In the present cases, it is not the case that its being necessarily the case that $P$ rather than its being possibly the case that $P$ explains why $P$, whereas in the intended instances of explanation by status it is the case that its being necessarily the case that $P$ rather than its being possible that $P$ explains why $P$.
} 
of the example that any truth is grounded in its being possible, we should not conclude on its basis that any necessary truth is grounded in its being necessary. ${ }^{27}$

"Being necessarily the case" as a determinate of "being the case": To address the above arguments against the of instances of ' $[\square P]$ grounds $[P]$ ', one might try to provide an account of how these could be true, i.e. how a fact $[\square P]$ could in principle be a ground for $[P]$. Here I want to consider one rationale for the corresponding grounding relation to obtain and for the logic of ground to be revised in a way that allows for them: Consider the idea that the properties expressed by 'is necessarily the case' and 'is contingently the case' are determinates of the same determinable, namely the property expressed by 'is the case'. This is not implausible, for being necessarily the case and being contingently the case seem to be different, more specific, and mutually exclusive ways of being the case. Plausible are also the corresponding grounding statements that follow, if we then apply the common assumption that instances of determinates ground instances of corresponding determinables:

(3) $[[P]$ is necessarily the case $]$ grounds $[[P]$ is the case $]$.

(4) $[[P]$ is contingently the case $]$ grounds $[[P]$ is the case $]$.

Note that given the plausible assumption that if $[P]$ is the case, then $[P]$ grounds $[[P]$ is the case $]$, we obtain two grounds for the fact $[[P]$ is the case $]$, namely $[P]$ and either $[[P]$ is necessarily the case] or $[[P]$ is contingently the case]. With respect to making sense of the schema ' $[\square P]$ grounds $[P]$ ', note that from the two schemata above the following do at least not obviously follow (let us use ' $\circ$ ' as a sentential operator that expresses contingent obtaining):

(5) $[\square P]$ grounds $[P]$.

(6) $[\circ P]$ grounds $[P]$.

I suspect that some of the appeal of (5) results from uncritically moving from (3) to (5). In any case, $[P$ because contingently, $P$ ] appears quite implausible, but this follows from the proposal for contingently true propositions $[P]$. Proponents of instances of ' $P$ because $\square P$ ' often claim that the necessary status of propositions affords somehow particularly good explanations, but if explanation by necessity is understood as just sketched, it is unclear how the special quality of such explanations should be accounted for, given that contingent status would provide an analogous explanation.

Taking stock: Intuition, the theoretical applications, as well as the promise of a kind of ultimate explanation lend support to the idea of explanation by status that should not be neglected. The extraordinary cases as well as the consideration from determinables and determinates moreover show how instances of ' $P$ because $\square P$ ' with corresponding grounding relations could be made sense of. But we have also seen that neither consideration makes sense of the intended kind of explanation by status. Rather, they suggest that status propositions do not play the role of grounds (and perhaps more generally reasons why the explanandum obtains) in proper explanations by status.

\footnotetext{
27 This gives us reason to suspect that the consideration involving the determination constraint from Sect. 1 is not quite correct. I believe that this problem can be addressed by formulating a determination constraint for the case of explanation by status that is restricted in a way that excludes the problematic case above, but for reasons of space I cannot go into detail here.
} 


\section{Generalization and reactions}

Let us see how the above generalizes to the cases of explanation by essential and law status, conceived of as instances of the schemata ' $P$ because it is an essential truth that $P$ ' and ' $P$ because it is a law of metaphysics (or nature) that $P$ '. The considerations in favor of explanation by modal status generalize straightforwardly. The situation concerning the arguments against explanation by modal status is this: The intuitive doubts, the problem of grounding elimination, and the regress problem generalize. ${ }^{28}$ The problem from reductive theories of modality only generalizes if there are suitable reductive theories of essence and lawhood. While it may be easy enough to formulate such theories, it is unclear how seriously they should be considered and how important their theoretical possibility is. While the case against explanation by essential and law status may thus be a little weaker than the case against explanation by modal status, it is still significant.

I now discuss two reactions to the above considerations for and against explanation by modal, essential and law status. The first denies that explanations by status exist. The second substitutes grounding by a different explanatory notion to figure in the links of these explanations.

One can deny the existence of explanation by status and accommodate the underlying intuitions and motivations differently. ${ }^{29}$ To this effect, Kappes and Schnieder (2016, 557f.) have suggested that the intuitive appeal of the relevant instances of ' $P$ because $\square P$ ' could stem from pragmatic effects. For example, asking 'Why $P$ ?' may often conversationally presuppose that it is possible that not $P$, and in such a case, pointing out the necessary status of $P$ may be a conversationally appropriate move: Not as an act of explaining why $P$ and thereby giving a correct answer to the question, but rather as rejecting one of the presuppositions of the question. As Kappes and Schnieder also mention, pointing out the necessity of a proposition can further epistemic goals (such as increasing the probabilistic coherence of one's belief-system) that explanation proper also often aims at. For example, explanation often serves the purpose of making facts less surprising, and pointing out that a fact is necessary may serve the same purpose: Coming to see that something could not have been otherwise may make it less surprising that things are that way. ${ }^{30}$

I consider these plausible fallback options should it turn out that explanation by status cannot be understood as explanation proper. Now, according to Glazier (2017a, b), explanation by essential and modal status can be so understood, but not as grounding explanation, but rather as involving different sui generis explanatory relations. ${ }^{31}$

\footnotetext{
28 The latter holds given the plausible assumption that essential and law status iterate. Cf. Fine (1995) for iteration of essential status.

29 Below I will sometimes only mention explanation by necessary status, but explanation by essential and law status are meant as well.

30 Cf. Schupbach and Sprenger (2011).

31 Bertrand's (2019a,b) "Explanation by constraint" is closely related to explanation by essential status and his account of it bears some resemblance to Glazier's. For example, Bertrand also argues against understanding these explanations in terms of grounding. It would be interesting to investigate to what extent explanation by constraint could be captured by my own account. Thanks to a referee of this journal here!
} 
Some features of Glazier's proposal raise initial scepticism: First, because new explanatory relations are postulated, Glazier's proposal incurs corresponding ideological commitments. Second, Glazier postulates his explanatory relations without stating much more than their being instantiated in the paradigmatic cases and their being distinct from grounding. Third, the postulated explanatory relations exhibit a weirdness that neither grounding nor, arguably, causation share: They form explanatory chains that necessarily have a final explanandum which is distinct in kind from its other elements (i.e. an explanandum that cannot explain a further proposition by standing in the same explanatory relation to it). This is the non-modal-box-prefixed or non-essential-box-prefixed proposition in which an explanatory chain of box-prefixed propositions that explain it terminates. Contrast this with the case of grounding, where each proposition grounds other propositions and with the case of causation, where it is plausible that each effect can at least in principle be a cause. ${ }^{32}$

Let us see to what extent the above discussion against explanation from status generalizes to Glazier's proposal: Intuitive doubts and an explanatory regress arise for this proposal too, but it avoids the problem from grounding elimination rules by stipulation. Insofar as reductive theories of modality are formulated in terms of grounding and not Glazier's necessitarian explanation, his proposal can avoid some of the problems of Sect. 2, but explanatory circles involving both grounding and necessitarian explanation still threaten to arise. Whether these are problematic is a matter we will turn to momentarily.

Now, note that the plausibility of the generality of the schema ' $P$ because $\square P$ ' (and its variants involving other statuses) is not affected by assuming a different explanatory relation than grounding to be involved. Furthermore, the determination constraint argument above does not appear to rely on features of grounding specifically, but rather on features of complete metaphysical explanation more generally. In any case, Glazier (2017a) accepts the generality of the schema. Given this, one problem for BECAUSE$\square$ that he considers is that (as we have noted above) one might want iterated-box claims to be (grounding-) explained by single-box claims, which would result in explanatory circles: Single-box claims would be explained by iterated-box claims and iteratedbox claims would be explained by single-box claims. To avoid this problem, Glazier suggests that the two explanations should be taken as explanations with different kinds of explanatory links: necessitarian explanation in the first case, grounding in the second. The suggestion is then that these two kinds of explanatory links are not in harmony, meaning that the disjunction of the two kinds of links need not satisfy structural properties such as asymmetry, irreflexivity, and transitivity, which are often ascribed to explanatory notions like grounding. ${ }^{33}$ Thus Glazier can claim that circles involving only grounding explanations are inadmissible because of the asymmetry and transitivity of grounding, while allowing for circles comprised of multiple kinds of explanation, e.g. grounding explanation and necessitarian explanation.

Whether explanatory links in general need to obey harmony is still an open question, but the disharmony of grounding and explanation by necessity would result in a significant theoretical cost: Explanation by necessity has been suggested as a kind

32 Below we will see that my own account avoids these problems.

33 The same point applies to the "Problems for certain theories of modality" in Sect. 2. 
of ultimate explanation, perhaps with some sort of principle of sufficient reason in the background. Now suppose that $[\square P]$ "explains-by-necessity" $[P]$ and that $[P]$ grounds $[Q]$. Then the most straightforward way of ultimately explaining $[Q]$ would be by invoking transitivity, but since the two kinds of explanation are supposed to be in disharmony, this is not possible.

Perhaps there is another way to achieve the desired ultimate explanation: Supposing that $[Q]$ is also necessary, $[Q]$ can be explained by its own necessity. ${ }^{34}$ But while each of $[P]$ and $[Q]$ is then explained by its own necessity, we do not obtain the more desirable result that both $[P]$ and $[Q]$ are explained in $[P]$ 's necessity. Perhaps this result can be obtained by assuming that $[\square P]$ explains $[\square Q]$, but then the involved explanatory relation would have to be in harmony with necessitarian explanation to allow chaining it with the explanation of $[Q]$ by $[\square Q]$. Therefore it cannot be grounding, since by assumption, grounding is not in harmony with explanation by necessity. Assuming that the relation is neither grounding nor Glazier's necessitarian explanation on the other hand seems ad hoc and unparsimonious. But it also cannot be necessitarian explanation because it does not involve explaining a proposition by its being necessary, which Glazier $(2017 \mathrm{a}, 12)$ stipulates is required for necessitarian explanation. ${ }^{35}$

\section{Empty-base explanation}

My own account of explanations by status employs the notion of an empty-base explanation. Recall the tripartite distinction between explanatory sources, links, and result_ - as it turns out, not every explanation does indeed require all three: There are possible explanations which do not have sources, i.e. explanations whose base is the empty set of propositions. I will call these explanations without sources 'empty-base explanations'.

Since the sources of an explanation why $P$ are reasons why $P$, while the corresponding explanatory link is (ignoring certain exceptional cases) not a reason why $P$, empty-base explanations why $P$ are explanations that (again ignoring some exceptional cases) do not involve reasons why $P$. As for because-statements that correspond to empty-base explanations, we use ' $\emptyset$ ' to stand for the empty set of reasons (i.e. the empty base of the corresponding explanation), which gives us ' ... because $\emptyset$ '. ${ }^{36}$

I will now argue that empty-base explanation is possible. In the next section, I will present my account of explanation by status as empty-base explanation, which will

\footnotetext{
${ }^{34}$ We can simply stipulate $[Q]$ 's necessity, but given grounding necessitarianism it follows if $[P]$ fully grounds $[Q]$.

35 Furthermore, necessitarian explanation would mirror grounding in the sense that $[P]$ grounds $[Q]$ and $[\square P]$ explains-by-necessity $[\square Q]$. But then it would be ad hoc if necessitarian explanation would not mirror grounding everywhere in the sense that for every necessary $[P]$ and $[Q]$, if $[P]$ grounds $[Q]$ then $[\square P]$ explains-by-necessity $[\square Q]$. This again would face the following problem: According to the above assumptions, $[\square \square \square P]$ explains-by-necessity $[\square \square P]$, and $[\square P]$ grounds $[\square \square P]$. But if necessitarian explanation mirrors grounding here, it also follows that $[\square \square P]$ explains-by-necessity $[\square \square \square P]$, violating asymmetry.

36 Somewhat tongue-in-cheek, we could also adapt the natural language expression 'just because', giving us '.. just because'.
} 
further support the latter's possibility. Now, consider some paradigmatic examples for links of metaphysical explanations:

(G) That the sun is crimson grounds that the sun is red.

(M) It is a metaphysical law that if something is in physical state $s$, then it is in mental state $m$.

(E) It is true in virtue of the essence of $\{$ Socrates $\}$ that if Socrates exists, $\{$ Socrates $\}$ exists.

Of the involved metaphysical notions, grounding is perhaps most widely discussed as an explanatory notion, but metaphysical laws and essential dependence have been discussed as explanatory notions as well. ${ }^{37}$ Normally, these links connect an explanatory source (viz. a reason why $P$ ) with an explanatory result (the proposition that $P$ ). I assume that in the case of metaphysical law and essential dependence, the explanatory links can be expressed by sentences of the form ' $\mathbf{\square}(P \rightarrow Q)$ ' or ' $\square \forall x(F x \rightarrow G x)$ '. But as it turns out, there are unconditional metaphysical-law-propositions and essential propositions of the form ' $\square Q$ ', for example:

$\left(\mathrm{M}^{*}\right)$ It is a metaphysical law that the empty set exists.

(E*) It is true in virtue of the essence of disjunction and negation that $P \vee \neg P .38$

Some such propositions are arguably true - the reader may substitute their favorite examples here; theists for example may consider the idea that it is a metaphysical law that God exists, or that it is true in virtue of the essence of God that they exist. In what follows, I argue that propositions like these can be links of empty-base explanations. ${ }^{39}$

But before, I will consider the case of grounding facts, which differ in form from the links just considered. Following Fine (2012) I assume that factive grounding facts are expressed by sentences of the form ' $\Gamma<\phi$ ', and non-factive grounding facts are expressed by sentences of the form ' $\Gamma \Rightarrow \phi$ ', where ' $\phi$ ' expresses the groundee and ' $\Gamma$ ' stands for a plurality of grounds. ${ }^{40}$

Normally, grounding is taken to be (at least something like) a relation between a plurality of propositions or facts (the grounds) and a single proposition or fact (the grounded fact or groundee), but Fine (2012, 47f.) has argued that we allow for zero-grounding, a limiting case of grounding in which the set of grounds is empty. A zero-grounded proposition or fact is grounded, but it does not require any propositions or facts to ground it-it is grounded in zero propositions. More precisely, grounding statements have the form ' $\Gamma<\phi$ ' and in the case of zero-grounding statements, the

\footnotetext{
37 For example, for grounding see Fine (2001), Rosen (2010), Schaffer (2009), and the papers in Correia and Schnieder (2012); for metaphysical laws Schaffer (2017, 2018), Kment (2014), and Wilsch (2016); for essential dependence Schnieder (2010) and Kment (2014).

38 Cf. Glazier (2017b) and Kappes (2020).

39 For a complication see footnote 47 . Note that I am not committed to the success of any particular of the given candidates for empty-base explanations-I argue for the possibility of empty-base explanation; it is a further question whether this kind of explanation is instantiated.

40 A note on the distinction between factive and non-factive grounding: Statements of the latter in contrast to statements of the former do not entail the truth of their clauses. Like laws of nature, they express an explanatory relation between propositions (or states of affairs) without entailing that the latter are true (or obtain). To give a further approximate gloss on the notion, non-factive grounding statements can be thought of as expressing potential factive grounding facts.
} 
' $\Gamma$ ' stands for an empty plurality of grounds, so statements of zero-grounding have the form ' $<Q$ ' ${ }^{41}$

Fine's motivation for zero-grounding is primarily technical: It is possible to generalize the notion of conjunction to apply to arbitrary sets of propositions such that a conjunction of a set $M$ of propositions is true iff all propositions in $M$ are true. This generalization gives rise to the empty conjunction [ $\searrow \emptyset]$, i.e. the conjunction of the empty set of propositions which is true iff all propositions in the empty set of propositions is true and hence is true. Fine reasons that because it is a principle of grounding that true conjunctions are grounded in their conjuncts taken together, $[\wedge \emptyset]$ is zero-grounded: It is grounded in its conjuncts taken together and thus grounded, but grounded in zero propositions:

$$
\left(\mathrm{G}^{*}\right)<\bigwedge \varnothing .
$$

An important point here is that general grounding principles can have instances of zero-grounding as limiting cases. ${ }^{42}$ By now, several applications and further candidates for zero-grounding have been offered in the literature. ${ }^{43}$

We can now argue that propositions like $\mathrm{M}^{*}, \mathrm{E}^{*}$, and $\mathrm{G}^{*}$ can indeed be links of empty-base explanations by extrapolating from the use of links such as M, E, and G in more ordinary explanations. In the ordinary case, these principles characterize how we can, in a sense, move from the base of an explanation to its result. For a successful explanation, both base and link are required: We start with the base and arrive at the result with the help of an explanatory principle. Schematically, the structure of such explanations is this:

$\begin{array}{lll} & \text { Metaphysical Law / Essence: } & \text { Grounding: } \\ \text { Base: } & P & P \\ \text { Link: } & \square(P \rightarrow Q) & P<Q \\ \text { Result: } & Q & Q\end{array}$

Now consider $\mathrm{M}^{*}$ and $\mathrm{E}^{*}$ : Might the first not explain why the empty set exists and the second why $P \vee \neg P$ ? Metaphorically speaking, in ordinary explanations that conform to the above schema, the reasons in the explanatory base and the explanatory link have to work together to explain the result. $\mathrm{M}^{*}$ and $\mathrm{E}^{*}$ appear play a similar explanatory role, but in their case, no help from explanatory sources is needed. Likewise, in the case of zero-grounding (e.g. $\mathrm{G}^{*}$ ), no reason is required for the link to explanatorily generate the result from an empty base-from nothing, so to speak (note the structural analogy between the grounding case and that of $\mathrm{E}^{*}$ and $\mathrm{M}^{*}$ ):

\footnotetext{
41 Matters are analogous for non-factive grounding.

42 Another argument for the existence of zero-grounding can be extracted from Fine's writings: Assuming his (2017a and 2017b) truthmaker account of propositions and grounding, the existence of zero-grounded propositions follows, but for reasons of space, I cannot go into detail here.

43 Litland (2012, 47f.) suggest that certain essentially obtaining truths are zero-grounded, Litland (2017) argues that non-factive grounding claims are zero-grounded, Muñoz (2020) argues for a role of zerogrounding in accounting for negative facts, and De Rizzo (2020) as well as Kappes (2020) consider logical theorems as candidates for zero-grounding.
} 


$\begin{array}{lll} & \text { Metaphysical Law / Essence: } & \text { Grounding: } \\ \text { Base: } & / & / \\ \text { Link: } & \mathbf{Q} Q & <Q \\ \text { Result: } & Q & Q^{44}\end{array}$

Litland (2017) further motivates empty-base explanation with the idea of explanatory arguments by first arguing for conditions under which arguments are explanatory, and then arguing that some arguments which have an empty set of premises satisfy the conditions; these arguments correspond to empty-base explanations. Given that M, E, and $\mathrm{G}$ correspond to to explanatory arguments, it is natural to assume that $\mathrm{M}^{*}, \mathrm{E}^{*}$, and $\mathrm{G}^{*}$ correspond to explanatory arguments without premises. ${ }^{44,45}$

Given the popular idea that explanation traces explanatory links which in turn involve explanatory notions, the idea of empty-base explanations can be motivated by the existence of propositions of form ' $\square Q$ ' or ' $<Q$ ' as follows. ${ }^{46}$ Since essential dependence, metaphysical lawhood and grounding are all explanatory notions that figure in the link component of corresponding explanations, we can ask what kind of explanation corresponds to propositions such as $\mathrm{E}^{*}, \mathrm{M}^{*}$, and $\mathrm{G}^{*}$. The answer is that these are empty-base explanations with unconditional essential propositions, unconditional metaphysical law-propositions, or zero-ground propositions as their link.

This can be developed as follows: Explanation traces links featuring multi-grade explanatory priority relations (e.g. essential dependence, metaphysical lawhood, or grounding) relating an explanandum with a plurality of explanatory sources. As the case of zero-grounding shows, this plurality can be empty. Cases of zero-grounding are thus instances of the very same explanatory notion, grounding, and we should conclude that in such cases, we deal with some sort of explanation as well. Given this picture, both ordinary and empty-base (i.e. zero-ground) grounding explanations have a link of form ' $\Gamma<Q$ ' (in case of zero-grounding, ' $\Gamma$ ' stands for an empty plurality of grounds). ${ }^{47}$

\footnotetext{
44 In their discussion of zero-grounding, Fine (2012) and Litland (2017) offer a similar metaphor of grounding as a machine that generates truths from inputs and zero-grounded truths from zero inputs. The idea can be straightforwardly applied to explanation in general.

45 Litland constructs am explanatory calculus to argue that there are explanatory arguments without premises with non-factive grounding statements as conclusions. Note that if this argument should ultimately be rejected yet nevertheless be intelligible, the idea of explanatory arguments would still support the intelligibility of empty-base explanation.

46 The locus classicus for the idea that explanation traces explanatory links (or corresponding explanatory relations) is Kim (1994). See also Schnieder (2010) for a corresponding suggestion concerning 'because' claims.

47 It is not quite clear whether we can conceive of $\mathrm{E}^{*}$ and $\mathrm{M}^{*}$ as relating an empty plurality of reasons with an explanatory result. As I have construed them, ordinary laws and essential dependence links have the form of a conditional prefixed with an operator. It is possible to treat this operator and the conditional together as one operator (schematically: ' $\mathbf{\square}(\ldots \rightarrow \ldots)$ )', which relates a plurality of explanatory sources to an explanatory result. We can then allow for an empty plurality of explanatory sources with the corresponding links having form ' $\mathbf{\square}(\Gamma \rightarrow Q)$ ', where ' $\Gamma$ ' stands for an empty plurality of propositions.

These links would have the same form as ordinary links involving essential dependence and metaphysical lawhood, the only difference being that in the case of empty-base explanations, ' $\Gamma$ ' stands for an empty plurality of explanatory sources. But this would not quite match my assumption that the form of these
} 
That explanations trace explanatory links does not logically entail that each emptybase explanatory link corresponds to an explanation. Nevertheless, assuming that for every ordinary explanatory link there appears to be an explanation that traces it, and in light of the other considerations, we should assume that empty-base explanatory links also correspond to explanations. At least, there appears to be no reason to treat the candidates for empty-base explanatory links systematically different: We are dealing with interesting limiting instances of ordinary explanatory notions and should accordingly conclude that there is an interesting corresponding limiting case of explanation as well.

\section{Explanation by status as empty-base explanation}

Equipped with the notion of empty-base explanation, we can now better understand explanation by status. Above we have assumed that in explanations by status, the status proposition is a reason why the explanandum obtains. For example, we have assumed that in the case of an explanation by necessary status, $[\square P]$ is a reason why $[P]$ obtains, and correspondingly [ $P$ because $\square P$ ] should be the case. But given the idea of empty-base explanation, we can drop this assumption and suggest that at least some proposals for explanation by status where $[P]$ is explained by a fact or proposition of form ' $\square P$ ' (where ' $\square$ ' stands for the relevant operator) are best understood as emptybase explanations in which $[\square]$ is not a reason why the explanandum $[P]$ obtains, but the explanatory link of an empty-base explanation why $P$. As the reflections of the previous section show, this idea is independently plausible.

According to this proposal, explanations by status do not correspond to 'because' claims of form ' $P$ because $\boldsymbol{\square} P$ ', since the status-proposition is not a reason why the explanandum obtains. Rather, as a link of an empty-base explanation, the statusproposition underlies a 'because' claim of the form ' $P$ because $\emptyset$ ' (or ' $P$ just because'). Consider for example the idea that we can explain why the empty set exists by pointing out that it is a metaphysical law that the empty set exists. The answer to the corresponding 'why' question is that the empty set exists because $\emptyset .{ }^{48}$

In explanations by zero-grounding, the zero-grounding fact helps explain the explanandum in the capacity of explanatory link. Therefore, the explanatory role of a status proposition of the form ' $\boldsymbol{\square} P$ ' in an explanation by status and the explanatory role of a zero-grounding fact in an explanation by zero-grounding are the same according to the present proposal. Hence, explanations by zero-grounding can be understood as a kind of explanation by status: In a zero-grounding explanation, the explanandum is explained by its status as a zero-grounded proposition. One notable result of understanding explanation by status as empty-base explanation is that the two

Footnote 47 continued

links is ' $\mathbf{\square} Q$ ', involving no conditionals or empty pluralities. One reaction here would be to revise this assumption, the other to be more lenient concerning the form of explanatory links (or argue that [ $Q$ ] and $[\boldsymbol{\square}(\Gamma \rightarrow Q)]$ play the same link-role). Deciding this matter requires a deeper investigation into the the nature of laws and explanation via essential connection than I can provide here. My suggestion is therefore to allow that propositions of the form ' $\square P$ ' can be explanatory links, but to keep in mind that the alternative form ' $\square(\Gamma \rightarrow Q)$ ' is available.

48 Alternatively: The empty set exists just because. 
ideas support each other: The notion of empty-base explanation allows us to better understand explanation by status, but likewise, the idea of explanation by status lets us better understand the notion of empty-base explanation and related ideas like zerogrounding. Intuitions about certain explanations by status being good, appropriate, or apt to create understanding why, thus also support the possibility of empty-base explanation and zero-grounding.

According to the present proposal, the metaphysical law involved in explanation by metaphysical law plays an explanatory role analogous to the role of a metaphysical law in an ordinary metaphysical-law-involving explanation, in which a metaphysical law links an explanandum $[P]$ and a reason why $P$. This seems intuitively correct, as well as theoretically more elegant and parsimonious than the rival proposals, which either forbid explanation by metaphysical law status or require stipulation of sui generis explanatory relations to locate the metaphysical law in the role of reason why rather than explanatory link. ${ }^{49}$

Having realized this for the case of explanation by metaphysical law, we should treat proposals for explanation by necessary or essential status analogously, since the status proposition in them plays the same explanatory role as the metaphysical law does in an explanation by metaphysical law status (that of an explanatory link). If explanation by essential status is possible, it should work analogously to explanation by metaphysical law status, namely conforming to the foil of empty-base explanation: The empty-base account of explanation by status naturally reveals explanation by metaphysical law and essential status as a special cases of explanations in which metaphysical laws or certain essential dependence relations play the role of explanatory links. Given the account, there is no reason to assume that explanation by metaphysical law or essential status involves grounding-claims of the form ' $[\boldsymbol{\square} P]$ grounds $[P]$ ' or analogous claims involving sui generis explanatory relations.

Now, it turns out that the account of explanation by status as empty-base explanation predicts that explanation by modal status is not possible: Explanation by status conceived as empty-base explanation requires that the status propositions are explanatory links, but propositions expressing necessary status cannot be such links. The equivalent of these links in non-empty-base explanations would be strict conditionals, but there are well known reasons against the thesis that metaphysical necessity is an explanatory notion and thus against the thesis that strict conditionals can be explanatory links. For example, explanatory links are asymmetric, but modal dependence (as captured by strict conditionals) is not. ${ }^{50}$ While one may perhaps accept some instances of symmetric explanation, modal dependence has many symmetric instances without corresponding explanatory connection; in general, explanatory links only connect explanatorily relevant relata, but strict conditionals also connect explanatorily irrelevant relata. For example: (i) modal dependence is reflexive, but explanation is irreflexive (perhaps given some exceptions); (ii) any two necessary truths are modally

49 Recall footnote 47 here, according to which the links of empty-base explanations might have the form ' $\mathbf{\square}(\Gamma \rightarrow P)$ ', with ' $\Gamma$ ' standing for an empty plurality of propositions, rather than the form ' $\boldsymbol{\square} P$ '. If that is the case, a proposal for an explanation why $[P]$ in terms of $[\mathbf{D} P]$ would best be understood as gesturing at a proper explanation in the vicinity, namely the empty-base explanation of $[P]$ which has $[\mathbf{\square}(\Gamma \rightarrow P)]$ as its link.

50 Cf. Schnieder (2015) on the asymmetry of explanation and explanatory links, as well as further references. 
equivalent, but neither need explain the other; (iii) [snow is white] is true because snow is white and not vice versa, but [snow is white] and [[snow is white] is true] are modally equivalent.

While I am thus inclined to discard the idea of explanation by modal status, it may (in addition to the options of Sect. 4) often be possible to substitute proposals for explanation by modal status by viable proposals for empty-base explanations involving zero-grounding explanation, metaphysical law, or essence. Here, two advantages of my proposal over Glazier's are that by treating explanation by status as a special (namely empty-base) case of ordinary kinds of explanations, my proposal demystifies explanation by status and allows for an assessment of candidates for explanations by status as (empty-base) special cases of ordinary kinds of explanations. In turn, like explanation by modal status, not all cases of proposals for explanation by status can be captured one to one. ${ }^{51}$

Let us consider now whether any of the problems for explanation by status discussed above carry over to explanation by status conceived of as empty-base explanation. Note first that the proposal deals well with the conflicted intuitive assessment of proposals of explanation by status: To an extent, intuition counts against explanation by status if we understand it as suggesting status propositions as reasons why, but it can count in favor of explanation by status if we understand the latter as emptybase explanation. One worry is that proposals for explanations by status often do not satisfy the inquirers (perhaps because they lack a feeling of understanding why), but we should not dismiss explanation by status on this basis alone. First, rival intuitions exist to the effect that explanation by status does provide understanding why. Second, assuming that understanding why requires properly grasping an explanatory link (as e.g. Hills (2016) effectively argues), an explanation of the absence of understanding why in the relevant cases is available: The subjects in question do not properly grasp the relevant explanatory link. Third, subjects sceptical of attempts at explanation by status might expect an explanation with features that explanations by status do not have (e.g. reasons why its explanandum obtains). But then rather than being no explanation, as the subjects intuit, it is merely not the kind of explanation they desire.

Turning to the other considerations against explanation by status: The worry from the grounding elimination rules does not carry over, because no grounding relation between the explanandum and the status proposition is postulated. Concerning the regress worry we have to note that a sort of regress presumably arises. For instance, in the case of zero-grounding, a regress starts with a zero-grounded proposition if we assume that zero-grounding claims are themselves zero-grounded (cf. Litland (2017)). This is not a regress of reasons why but a regress of explanatory links: Except for the first element of the regress, each element is a link in an empty-base explanation of the previous element. Where discussed, this regress is considered to be unproblematic. ${ }^{52}$ A principled account of why a regress of grounds should be problematic but a regress of explanatory links not would clearly be desirable, but to my knowledge has not yet

\footnotetext{
51 In principle, van Inwagen's proposal for explanation by high probability can be assessed like this too: Determine a corresponding candidate for explanatory link (some sort of probabilistic conditional presumably) and assess whether it can indeed be an explanatory link.

52 See e.g. Bennett (2011) and Litland (2017).
} 
been given. Finally, as far as I can see, the other problems for explanation by status do not arise for empty-base explanation.

\section{Conclusion}

The account of explanation by status as empty-base explanation defends and develops the practice of explanation by status as a limiting case of ordinary explanation and thereby removes some of the mystery surrounding the practice. Three virtues of the account are that (i) it allows for the possibility of explanation by status as a proper kind of explanation, (ii) it achieves this without postulating sui generis explanatory relations, and (iii) it provides a method to determine which kinds of status allow for a corresponding kind of explanation by status.

Acknowledgements Special thanks to Benjamin Schnieder, Stephan Krämer, Stefan Roski, and an anonymous referee for this journal for very valuable discussion, encouragement, and comments. I also thank the Deutsche Forschungsgemeinschaft for funding work on this paper through the project The Structure of Fundamentality (Grant No. SCHN 1137/5-1).

Funding Open Access funding enabled and organized by Projekt DEAL.

\section{Compliance with ethical standards}

Conflict of interest The authors declare that they have no conflict of interest.

Open Access This article is licensed under a Creative Commons Attribution 4.0 International License, which permits use, sharing, adaptation, distribution and reproduction in any medium or format, as long as you give appropriate credit to the original author(s) and the source, provide a link to the Creative Commons licence, and indicate if changes were made. The images or other third party material in this article are included in the article's Creative Commons licence, unless indicated otherwise in a credit line to the material. If material is not included in the article's Creative Commons licence and your intended use is not permitted by statutory regulation or exceeds the permitted use, you will need to obtain permission directly from the copyright holder. To view a copy of this licence, visit http://creativecommons.org/licenses/by/4.0/.

\section{References}

Bennett, K. (2011). By our bootstraps. Philosophical Perspectives, 25, 27-41.

Bertrand, M. (2019a). Metaphysical explanation by constraint. Erkenntnis, 84, 1325-1340.

Bertrand, M. (2019b). Metaphysical constraints, primitivism, and reduction. Journal of the American Philosophical Association, 5, 503-521.

Biggs, S. (2011). Abduction and modality. Philosophy and Phenomenological Research, 83, $283-326$.

Bliss, R. (2013). Viciousness and the structure of reality. Philosophical Studies, 166, 399-418.

Block, N., \& Stalnaker, R. (1999). Conceptual analysis, dualism, and the explanatory gap. Philosophical Review, 108, 1-46.

Correia, F., \& Schnieder, B. (2012). Grounding: an opinionated introduction. In F. Correia \& B. Schnieder (Eds.), Metaphysical grounding: Understanding the structure of reality. Cambridge: Cambridge University Press.

De Rizzo, J. (2020). Grounding grounds necessity. Analysis. https://doi.org/10.1093/analys/anz083.

deRossett, L. (2013). No free lunch. In M. Hoeltje, B. Schnieder, \& A. Steinberg (Eds.), Varieties of Dependence (pp. 243-270), Philosophia.

Fine, K. (1994). Essence and Modality. Philosophical Perspectives, 8, 1-16.

Fine, K. (1995). The logic of essence. Journal of Philosophical Logic, 24, 241-273. 
Fine, K. (2001). The question of realism. Philosophers'. Imprint, 1, 1-30.

Fine, K. (2010). Some puzzles of ground. Notre Dame Journal of Formal Logic, 51, 97-118.

Fine, K. (2012). Guide to ground. In F. Correia \& B. Schnieder (Eds.), Metaphysical grounding (pp. 37-80). Cambridge: Cambridge University Press.

Fine, K. (2017a). A theory of truthmaker content I: Conjunction, disjunction and negation. Journal of Philosophical Logic, 46, 625-674.

Fine, K. (2017b). A theory of truthmaker content II: Subject-matter, common content, remainder and ground. Journal of Philosophical Logic, 46, 675-702.

Glazier, M. (2017a). The difference between epistemic and metaphysical necessity. Synthese. https://doi. org/10.1007/s11229-017-1626-2.

Glazier, M. (2017b). Essentialist explanation. Philosophical Studies, 174, 2871-2889.

Hempel, C. G., \& Oppenheim, P. (1948). Studies in the logic of explanation. Philosophy of Science, 15, $135-175$.

Hill, C. S., \& McLaughlin, B. P. (1999). There are fewer things in reality than are dreamt of in Chalmers' philosophy. Philosophy and Phenomenological Research, 59, 445-454.

Hills, A. (2016). Understanding why. Noûs, 50, 661-688.

Kappes, Y. (2020). The explanation of logical theorems and reductive truthmakers. Philosophical Studies. https://doi.org/10.1007/s11098-020-01474-3.

Kappes, Y., \& Schnieder, B. (2016). Anything at all-the deepest and the shallowest question. Philosophisches Jahrbuch, 123, 543-565.

Kim, J. (1994). Explanatory knowledge and metaphysical dependence. Philosophical Issues, 5, 51-69.

Kment, B. (2014). Modality and Explanatory Reasoning. Oxford: Oxford University Press.

Kovacs, D. M. (2020). Metaphysically explanatory unification. Philosophical Studies, 177, 1659-1683.

Krämer, S. (2013). A simpler puzzle of ground. Thought: A Journal of Philosophy, 2, 85-89.

Lange, M. (2009a). Laws and Lawmakers: Science, Metaphysics, and the Laws of Nature. Oxford: Oxford University Press.

Lange, M. (2009b). Why do the laws explain why? In T. Handfield (Ed.), Dispositions and causes. Oxford: Oxford University Press.

Lange, M. (2013). Are some things naturally necessary? In Tyron Goldschmidt (Ed.), The puzzle of existence: Why is there something rather than nothing? (pp. 235-251). Abingdon: Routledge.

Leibniz, G. W. (1714). Principles of Nature and Grace, Based on Reason. In R. Ariew (transl.) \& D. Garber (Ed.), G. W. Leibniz. Philosophical Essays, Indianapolis: Hackett, 206-13.

Leslie, J. (2001). Infinite minds: A philosophical cosmology. Oxford: Oxford University Press.

Lewis, D. K. (1986). Causal explanation. In D. Lewis (Ed.), Philosophical papers (Vol. II, pp. 214-240). Oxford: Oxford University Press.

Litland, J. E. (2017). Grounding grounding. Oxford Studies in Metaphysics, 10, 279-315.

Muñoz, D. (2020). Grounding nonexistence. Inquiry: An Interdisciplinary Journal of Philosophy, 63, 209229.

Rabin, G. O., \& Rabern, B. (2016). Well founding grounding grounding. Journal of Philosophical Logic, 45, 349-379.

Rosen, G. (2010). Metaphysical dependence: Grounding and reduction. In B. Hale \& A. Hoffmann (Eds.), Modality: Metaphysics, logic, and epistemology (pp. 109-36). Oxford: Oxford University Press.

Rundle, B. (2004). Why There is Something Rather Than Nothing. Oxford: Oxford University Press.

Schaffer, J. (2009). On what grounds what. In D. Manley, D. J. Chalmers, \& R. Wasserman (Eds.), Metametaphysics: New essays on the foundations of Ontology (pp. 347-383). Oxford: Oxford University Press.

Schaffer, J. (2017). The ground between the gaps. Philosophers' Imprint, 17.

Schaffer, J. (2018). Laws for metaphysical explanation. Royal Institute of Philosophy Supplement, 82, 1-22.

Schnieder, B. (2010). A puzzle about 'because'. Logique Et Analyse, 53, 317-343.

Schnieder, B. (2011). A logic for 'because'. Review of Symbolic Logic, 4, 445-465.

Schnieder, B. (2015). The asymmetry of 'because'. Grazer Philosophische Studien, 91, 131-164.

Schupbach, J. N., \& Sprenger, J. (2011). The logic of explanatory power. Philosophy of Science, 78, 105127.

Skow, B. (2016). Reasons Why. Oxford, UK: Oxford University Press.

van Inwagen, P. (1996). Why is there anything at all? Aristotelian Society Supplementary, 70, 95-120.

Wilsch, T. (2016). The deductive-nomological account of metaphysical explanation. Australasian Journal of Philosophy, 94, 1-23. 
Woodward, J. (2003). Making Things Happen: A Theory of Causal Explanation. Oxford: Oxford University Press.

Yablo, S. (2014). Aboutness. Princeton: Princeton University Press.

Publisher's Note Springer Nature remains neutral with regard to jurisdictional claims in published maps and institutional affiliations. 